\title{
Sociedade, Fragmentação e Políticas Públicas Municipais
}

Márcia Rosa de Lima*

Cristiane Catarina Fagundes de Oliveira*

Resumo:

O Poder Executivo no Município elabora as políticas públicas dirigidas à sociedade local, que exige participação nos conselhos municipais. $\mathrm{O}$ fundamento da participação por meio dos conselhos municipais está na Constituição, no princípio da subsidiariedade e na ideia de fragmentação.

Palavras-chave: sociedade local - fragmetnação - políticas públicas - conselhos municipais

\begin{abstract}
:
The executive power in the municipality prepares public policies aimed at the local society, which requires participation in municipal councils. The foundation of participation through municipal councils is the Constitution, the principle of subsidiarity and the ideia of fragmentation.
\end{abstract}

Key-words: local society - fragmentation - public policies - municipal councils

* Graduada, mestre e doutora em Direito pela Pontifícia Universidade Católica do Rio Grande do Sul, com estágio de Doutorado na Faculdade de Direito de Lisboa com financiamento CAPES. Professora de Direito Administrativo no Curso de Especialização em Direito Municipal da Escola Superior de Direito Municipal. Procuradora Municipal de Porto Alegre.

* Graduada em Direito pela UFRGS. Mestre em Direito do Estado pela UFRGS. Doutora em Direito do Estado pela USP. Professora da Graduação e do Pós Graduação em Direito do UNILASSALE. Procuradora do Município de Porto Alegre. Diretora Administrativa da Escola Superior de Direito Municipal. 


\section{Introdução}

A administração pública dos municípios, que intervém de modo decisivo na vida da sociedade local, por meio das políticas públicas, deve ser fundada na participação social, em vista do princípio da subsidiariedade. A participação política, em que pese seu sentido amplo, será explicitada em relação aos conselhos municipais. Os conselhos municipais, em suas várias áreas de atuação podem ser considerados importantes instrumentos de participação e condução das políticas públicas.

\section{Sociedade, fragmentação e participação}

Um dos pressupostos da participação política é a compreensão das características da sociedade pós-moderna, para que os instrumentos de participação política sejam adequados, no sentido do tempo e das formas e no sentido da fragmentação e da singularidade. Se a sociedade tem características novas, então o direito deve estar a elas adequado (SCHWARTZ, 2015) e também os instrumentos de participação política.

Nesse sentido, afirma-se que é possível perceber, nos conceitos de política e não política, uma dissolução das fronteiras da política em que direitos estabelecidos reduzem margem de debate dentro do sistema estatal político e fazendo com que surjam fora do sistema demandas de participação política sob a forma de uma nova cultura política (BECK, 2013, p.278). Nesse sentido a participação política significa que os cidadãos conhecem os instrumentos de controle da atividade estatal.

Tradicionalmente a participação política pode ser entendida em três níveis de acordo com a intensidade da participação (SANI, 2004, p.889). O primeiro é no sentido de mera presença, em que não há grande contribuição pessoal, a segundo forma é de ativação, que ocorre dentro ou fora de uma organização política, quando a pessoa é incumbida de uma série de atividades permanentes ou esporádicas, por exemplo, quando há um envolvimento em campanhas eleitorais, quando se difunde a imprensa do partido, quando se participa em manifestações de protesto, etc. Um terceiro nível é de participação, em sentido estrito, em situações em que o indivíduo contribui direta, o que é muito raro, ou indiretamente, na escolha de representantes, por exemplo, para uma decisão política. A 
análise dos conselhos municipais envolve exatamente esse nível de participação em sentido estrito, como forma de participação.

No contexto exposto, afirma-se que os conselhos municipais são instrumentos de participação política que busca transitar entre o político-estatal e o não político, centrado na noção de sociedade civil ciente de seus direito. Ademais, os conselhos não se consubstanciam em forma de participação política direta, pois são instâncias de representação. São nesse sentido considerados como forma de participação política para controle da atividade estatal nos municípios.

Na gestão pública da atividade estatal, termo pelo qual se designa a estrutura político-burocrática do Estado de forma ampla, há um staff dirigente e executor das decisões públicas. Também a gestão pública municipal envolve a existência desse staff dirigente e executor em nível local. Em regra, a participação das pessoas da sociedade civil na gestão pública municipal, no sentido estrito acima descrito, concentra-se na escolha do staff dirigente por eleições, como no caso do chefe do Poder Executivo e dos representantes do Poder Legislativo. Tradicionalmente a eleição para o próprio governo local é considerada "manifestação mais cabal da soberania de um povo", conforme BRICCHI (1991, p.32). De outro lado, os eleitos se encarregam da elaboração da legislação relativa à seleção dos demais integrantes do staff, como, por exemplo, pelas regras do concurso público.

Entretanto, no atual contexto da atividade estatal é preciso considerar a fragmentação da idéia de execução na atividade estatal, considerando-se que a execução das competências e políticas públicas tem, cada vez mais sido atribuídas em sede de contratos com empresas privadas e cada vez menos a servidores públicos do staff estatal. Daí a análise da atividade estatal sob o prisma do conceito de parceria (DIPIETRO, 2015, p.23).

De outro lado, é possível analisar outras formas de participação em sentido estrito e interno na atividade estatal, que pode então ter dois sentidos. O primeiro sentido é interno à própria gestão pública, entre os níveis internos de decisão, isto é, interior à gestão pública na relação entre os membros do staff. Pode-se implementar a participação por órgãos colegiados cujo objetivo é descentralizar as decisões e permitir 
maior participação dos membros do staff. O segundo sentido é externo à gestão pública, na participação da sociedade municipal com pessoas, não integrantes do staff, escolhidas para opinar em certas situações, que é o caso de órgãos colegiados com a participação de membros da sociedade local: os conselhos municipais. Nesse sentido, os conselhos municipais são órgãos colegiados integrantes da estrutura administrativa de gestão pública municipal, integrado exclusivamente por membros da Administração Municipal ou também integrado por membros da sociedade.

A fim de estabelecer novos instrumentos de participação da sociedade, deve-se compreender a fundamentalidade do princípio de subsidiariedade, que em uma sociedade pluralista, (DIPIETRO, 2015, p.23) significa que a todos os setores da sociedade deve ser dada oportunidade de participação, diminuindo as barreiras entre Estado e Sociedade. Nesse sentido, os instrumentos jurídicos devem ser "formless", isto é, não podem estar fixados na modernidade das formas.

Com a Constituição de 1988 e a inserção do Município como ente federado, forma instituídas legislações infra-constitucionais que determinaram ao Município a definição de políticas públicas, como saúde, educação, infância e juventude. É um novo Estado Brasileiro com a descentralização e o ingresso da participação da sociedade através dos Conselhos Municipais, fundado na participação da sociedade local.

É possível estabelecer áreas de participação na gestão pública da atividade estatal, de acordo com etapas, que são de: planejamento, produção-execução administrativa e controle. Conforme FURLAN e CORROCHATEGOL (1989, p.58), o município tem duas funções: a representação da identidade e dos interesses locais frente a outras instâncias de organização estatal e a satisfação das necessidades públicas locais e a questão está em quem define as necessidades locais. Para estes autores, dependeria do tamanho do município e da participação. As etapas das políticas municipais e dos mecanismos de participação dos munícipes, dependem, para sua efetivação, de uma cultura de participação, e podem ser citados mecanismos específicos de participação de acordo com as etapas citadas: na área de planejamento, o planejamento participativo, as reuniões públicas, plebiscitos e referendos e manifestações em geral; na área de controle, ouvidorias, veto popular; e na área de produção e execução, a atividade cooperativa, gestão tripartida de serviços públicos e parcerias público-privadas. 
Assim, os conselhos municipais podem atuar em quaisquer dessas etapas das políticas e podem ser considerados mecanismos de participação em cada uma delas. No campo do planejamento, por exemplo, os mecanismos de participação do planejamento participativo e das reuniões abertas são semelhantes aos que ocorrem nos conselhos municipais. Em geral, a forma mais aceita de participação política é na etapa do planejamento, pois quanto maior o número de opiniões, mais amplo serão os projetos, o que interessa à gestão pública. Na área de controle os conselhos poderiam desempenhar um papel fundamental no sentido da dinamicidade, principalmente no que tange ao controle político, pois senão resta à sociedade aguardar para realizar a manifestação de um juízo político apenas nas próximas eleições. Na área de produção e execução seria interessante a participação por meio dos conselhos, pois diante de parcerias poderiam ser resolvidos vários problemas de ordem financeira para execução de políticas sociais, por exemplo.

A natureza das decisões tomadas no âmbito da participação das pessoas na gestão pública municipal pode ser de três formas: opinativa ou consultiva, isto é, sem força vinculatória; deliberativa ou decisória, isto é, que pode ser executada diretamente sem necessidade de homologação por órgão superior no staff da gestão pública; e de controle, relativas às decisões finais de verificação de atos de outros membros do staff da gestão pública.

Em relação à natureza opinativa ou consultiva, pode-se afirmar que apenas vincula no sentido de exigir a apresentação de motivação, especificamente em relação às objeções apontadas, ao ato da administração (PETRUCCI, 2015). A função deliberativa pode ser oposta à função opinativa ou consultiva, no sentido de que a função consultiva é de mera emissão de opinião para o órgão requerente da Administração, sendo que a função deliberativa seria sinônimo de decisória. As decisões de caráter deliberativo ou consultivo de conselho municipal (MARQUES, 2004, p. 54) relacionam-se à partilha do poder e um exemplo que evidencia a autonomia deliberativa de conselho é que sua presidência seja escolhida pelos próprios membros deste conselho. Todavia, muitos conselhos municipais são presididos por secretários do município, em especial no caso de conselhos de saúde. 
Em um sentido amplo de deliberação, identifica-se a idéia de discussão, emissão de opinião a fim de se tomar uma decisão. Essa acepção da função deliberativa, como ocorre nos Parlamentos, não significa uma simples tomada de decisão como "sim ou não", mas envolve o debate, discussão e influências políticas, conforme CAGGIANO (2004, p. 17-18).

Para tanto, pode-se referir quatro critérios para uma deliberação, conforme FISHKIN (2015) adequada ou, em outras palavras, as qualidades de uma deliberação: 1) informação precisa e razoável sobre os fatos, para possibilitar conclusões adequadas e precisas; 2) completude dialógica, que se relaciona à extensão com que os argumentos são apresentados, contraditos e reapresentados, o que difere da propaganda feita para persuadir, que omite estrategicamente parte das informações; 3) diversidade de pontos de vista, que exige um consenso mínimo e que difere das discordâncias na sociedade que não podem ser deliberadas; 4) participação consciente, sem visar fins prédeterminados, mas com objetivo de debater e ter sua opinião levada em conta para as políticas públicas.

Esses critérios deverão ser tomados na deliberação dos conselhos municipais, como forma de adequação à finalidade da participação política. Isso exige uma proximidade com a Administração Municipal para fins de troca de informações e de diálogo, bem como uma consciência da finalidade da sociedade municipal por parte dos membros do conselho municipal.

Os conselhos municipais têm essencialmente essa função deliberativa em sentido amplo, pois é da natureza de sua existência o debate e a discussão. Em relação à natureza de suas decisões - opinativa, deliberativa ou de controle, dependerá da legislação aplicável a cada conselho. A relevância dessas funções dos conselhos é descrita em BAVA (2015).

\section{Os conselhos municipais e a as definicões das Políticas Públicas}


Os conselhos municipais são uma realidade nos municípios brasileiros, segundo dados do IBGE, que mapeou a existência dos conselhos municipais em todos os 5.565 municípios brasileiros no último levantamento de 2012.

Destes 5.565 municípios brasileiros, em relação aos conselhos municipais de política urbana ou similar, 1231 municípios possuíam conselhos, mas apenas 888 deles tiveram reunião nos últimos 12 meses antes da pesquisa. Em relação a conselho de transporte, uma das mais relevantes políticas públicas municipais, dos 5565 municípios brasileiros, apenas 357 possuem tal conselho e 206 tiveram reunião nos últimos 12 meses.

É de se atentar que no levantamento do IBGE de 2004 havia apenas 334 conselhos municipais de política urbana. Em aproximadamente 10 anos houve crescimento significativo de número de conselhos. De outro uma realidade ainda se mantém desde os dados de 2004 que é o significativo número de conselhos municipais quando tais conselhos estão inseridos em políticas de tranferências de verbas, como conselho de saúde, assistência social, educação, etc... Ainda se percebe em praticamente todos os estados, o maior número de conselhos instalados é para o conselho de saúde, seguido pelo de educação.

Os conselhos municipais, portanto, estão em expansão, especialmente confrontando-se os dados dos últimos 10 anos, sendo que já os municípios menores os estão instituindo. Veja, contudo, que os conselhos instituídos no maior número de municípios são aqueles decorrentes de previsão em lei federal.

Dessa forma, os conselhos são expressão de democracia no plano local, instituídos em muitos casos por leis federais (SANTOS JUNIOR, 2001, p.18), na maioria dos casos com previsão expressa de representação paritária (MARQUES, 2004, p. 52), como no caso dos conselhos municipais de desenvolvimento rural (CMDR) ligados ao Programa Nacional de Fortalecimento da Agricultura Familiar. A participação, por exemplo, nos conselhos municipais de desenvolvimento rural, dá-se essencialmente por razões de distribuição de recursos, conforme pesquisa realizada em ANDRADE (2004, p.246-7), que conclui que: “... os parceiros locais estabelecem relações de cooperação, acima de tudo porque estão em jogo benefícios materiais. Tanto os produtores rurais, 
quanto os dirigentes sindicais e os representantes do poder público que participam do processo têm consciência dos benefícios que podem advir de sua participação nos fóruns de decisão do Pronaf e nas atividades realizadas pelo programa. $\mathrm{O}$ seu engajamento tem assim um componente explicativo forte nos interesses materiais dele decorrentes.”.

Os conselhos, então, tornam-se um mecanismo criado "de cima para baixo" conforme aponta MARQUES (2004, p.54), na busca de recursos financeiros, em que a realidade local não é levada em conta acerca da necessidade de participação em determinada matéria sob a forma de conselho municipal. A idéia federal de uniformizar os municípios representa uma contrariedade à realidade assimétrica dos municípios brasileiros.

A realidade dos municípios deve ser levada em conta na instituição de um conselho municipal em vários âmbitos, conforme SANTOS JUNIOR (2001, p.9596) pois: "Obrigatórios por lei federal em diversos setores (saúde, educação, criança e adolescente, assistência social e trabalho), os conselhos se diferenciam de acordo com o município: (i) pelo poder de decisão, deliberativo ou consultivo; (ii) pelos critérios de representação dos diferentes segmentos sociais, amplos ou restritos; e (iii) pela dinâmica e pelas condições de seu funcionamento, isto é, os instrumentos e a estrutura à sua disposição. Nesse sentido, entendemos que os conselhos municipais são a maior expressão da instituição, pelo menos no plano legal, do modelo de governança democrática no âmbito local."

Portanto, os municípios devem, ainda que sob pressão de necessidades financeiras e por exigência de legislação federal ou estadual, por exemplo, na instituição de conselhos municipais, procurar manter ao máximo a liberdade de conformação dos conselhos municipais. Senão, o município perderá a noção da necessidade de desenvolver a participação política em âmbito local a fim de melhor alcançar a finalidade do bem comum. Veja-se que a exigência de legislação federal ou estadual não tem fundamento constitucional eis que não há determinação de superioridade hierárquica em relação à legislação local (FERRAZ, 1988, p. 42-7).

De outro lado, as políticas públicas estabelecidas de forma participativa são uma exigência constitucional, especialmente com o surgimento de um 
catálogo de direitos sociais fundamentais. O Estado brasileiro redesenhou a estrutura organizacional do sistema de proteção aos direitos fundamentais. A primeira solução encontrada foi a descentralização das esferas de decisão e de responsabilidade pela implantação das políticas públicas setoriais. Exemplos desta alteração estrutural são o Sistema Único de Saúde, como proposto na Lei no 8080, de 19 de setembro de 1990 (que tem a regionalização como princípio); e o atendimento à educação que dividiu entre os entes federados as obrigações estruturais para ofertar o acesso, nos termos dos arts. 24 e 211 da Constituição brasileira de 1988. E o Estatuto da Criança e do Adolescente, que tem em seu art. 88 o princípio da municipalização do atendimento determinado. Em todos esses casos, a criação e a manutenção de conselhos foi fundamental ao estabelecimentos das políticas públicas.

Nesse sentido do estabelecimento das políticas públicas é que se afirma que, em relação à função dos conselhos municipais, mais importante que colocar sugestões, é discutir os problemas. Deve-se partir da idéia de que os cidadãos têm condições de identificar os problemas que mais os afligem, dentre vários, e discuti-los, como tentativa de busca de soluções. Daí o papel do município frente a sociedade local a fim de motivar a sociedade a buscar soluções próprias, assessorá-las para que possam melhor analisar os problemas, apoiando técnica e financeiramente a execução de projetos apoiados pela sociedade. A sociedade local é que deve organizar-se de acordo com suas necessidades, para o estabelecimento das políticas públicas, sendo que ao município, identificado com a estrutura da gestão pública municipal, caberá a tarefa de promover o debate, mas não substituí-lo, e, ao final, estabelecer o que for definido como política pública.

É importante que cada Município possa debater acerca das suas políticas públicas, a ser implementada por demanda da sociedade local, pelo Poder Público, pois dependendo da população dos municípios, as suas necessidades e os problemas públicos são diversos. Veja-se, por exemplo, que nos municípios grandes, em geral, debatem-se aspectos sociais do ambiente, marginalização, pobreza; nos intermediários, debilidade econômica, depredação dos recursos naturais, desigualdades sociais; e, nos pequenos, migração dos jovens, a própria viabilidade do governo local. Deve ser, nesse passo, questionada a idéia de que a imprensa massifica problemas sociais e os pequenos municípios tomam problemas que não são seus. 
Para a tarefa de identificar os seus problemas próprios, os conselhos municipais, em geral, estão ligados indistintamente às discussões em sede de associações de moradores, grupos comunitários, sociedades de natureza religiosa local, órgãos de classe, sindicatos, cooperativas, enfim, órgãos com as mais variadas naturezas (KRAUSE, 2002, p.60). Uma vez que sejam identificadas as discussões, será possível aos conselhos atuar na proposição das políticas públicas mais adequadas à sociedade local. A diversidade deve ser realçada positivamente pelos órgãos da gestão pública municipal, a fim de manter em união o espírito de identidade da sociedade local.

No estudo dos conselhos municipais é importante desde logo advertir que não se trata de passar ao povo o pleno direito de fixação das políticas públicas, mas apenas alicerçar, oferecer suporte e opiniões que serão ou não levadas em conta pelo detentor do poder político legítimo ou estrutural estatal.

Da mesma forma, não é possível passar à sociedade local o direito de tomada de decisões técnicas acerca de obras e serviços, pois para tal é necessário corpo técnico especializado (GOMEZ, 1991, p.59). De fato, torna-se necessário, na atribuição de tarefas no âmbito municipal, distinguir-se o âmbito técnico e o político.

De qualquer forma, a fim de fixar o papel dos conselhos municipais para o estabelecimento das políticas públicas, importante trazer à colação a proposta de Maria Paula Dallari Bucci (2006, p.39), em que a política pública deve visar a realização de objetivos definidos, expressando a seleção de prioridades e para que isto se concretize deverá também estabelecer a reserva de meios necessários à sua consecução e o intervalo de tempo em que se espera o atingimento dos resultados. Nesse sentido ainda, as políticas públicas, são "arranjos institucionais complexos, expressos em estratégias ou programas de ação governamental, que resultam de processos juridicamente regulados, visando adequar fins e meios"( BUCCI, 2008,p.250).

A relação nas políticas públicas torna-se complexa entre sociedade local e poderes de Estado, pois não sendo estes arranjos executados de forma que efetivem o direito, a sociedade local buscará o Judiciário, por exemplo, para verificar se as ações propostas e ou executadas pelo Executivo atendem o preceituado constitucionalmente e, se 
entender, que não está sendo efetivo modificará a política pública inicialmente estabelecida pelo Executivo naquele caso concreto. Daí as discussões sobre competência ente os entes federados e a harmonia e independência entre os poderes e fragmentação do próprio direito, temas que devem ser discutidos em vista da formação das políticas públicas de forma participativa.

Veja-se ainda, na complexidade da participação da sociedade local na formação das políticas públicas, deve ser percebido o fato de que elas vinculam a administração e não apenas os governos, que se alternam no poder. E, ainda, são formadas especialmente quando a sociedade local está organizada por meio dos Conselhos Municipais, instâncias deliberativas e opinativas, conforme sua classificação, definida no ato de criação. Assim, a política pública proposta a partir de determinação constitucional por força de participação da sociedade local é política de Estado (MARQUES NETO, 1998), independe da vontade do governante, que define apenas a política de governo .

\section{Conclusão}

Em vista da realidade da fragmentação, a sociedade local não se compreende como apartada da atividade estatal. Não se concebe o papel da sociedade e de suas demandas sem estarem ligadas à atividade do próprio município, na formação das políticas públicas.

A Administração Municipal, pela proximidade com a sociedade local, tem sido requerida para resolver questões relativas a habitação, saúde, insegurança e tantas outras com fundamento nos direitos elencados na Constituição de 1988. Entretanto, é mais possível imaginar-se a Administração Pública como provedor das soluções para todos os problemas sociais, sem que se considerem, para estas soluções, o debate fomentado na própria sociedade, de forma organizada, pelos conselhos municipais.

Neste contexto, destaca-se a importância dos conselhos municipais, como instâncias organizadas da sociedade local, para conduzir os debates sobre políticas públicas. O princípio da subsidiariedade é que fundamenta a existência dos conselhos municipais, no sentido da aproximação entre a sociedade local e a Administração Municipal. 
Os conselhos municipais são uma realidade brasileira, ainda que criados, em geral, por determinação de legislação federal ou por necessidades financeiras de repasses de verbas. Em virtude da diversidade entre os municípios brasileiros, a busca deve ser da preservação de suas peculiaridades locais, inclusive quanto à determinação dos problemas que os afligem, mas também para configurar, ao máximo, a organização própria de seus conselhos municipais. Para isso o conselho deve ser visto como um canal de diálogo e não de imposição de vontades, o que exige uma verdadeira representação no sentido da prudência a fim de tornar possível a convivência social voltada para o bem comum. E assim é que as políticas públicas poderão ser discutidas e conduzidas para esse bem comum.

\section{Bibliografia}

ANDRADE, Ilza Araújo Leão de. "Conselhos de desenvolvimento rural: um espaço adequado para pensar o desenvolvimento local?’.In: MARQUES, Paulo E. Moruzzi; SCHNEIDER, Sérgio; e SILVA, Marcelo Kunrath (org.). Políticas públicas e participação social no Brasil. Porto Alegre: Ed. UFRGS, 2004.

BAVA, Silvio Caccia. Dilemas da gestão municipal democrática. Disponível em http://polis.org.br/publicacoes/dilemas-da-gestao-municipal-democratica. Acessado em 19 maio 2015.

BECK, Ulrich. Sociedade de Risco. São Paulo: Editora 34, 2013.

BRICCHI, Adhemar Heriberto. Problemas del regimen y Gobierno Municipal. In: MÁRQUEZ, Daniel Alberto e PICONE, Francisco Humberto (Coord.). Temas de Derecho Municipal. Buenos Aires: Pensamiento Jurídico Editora, 1991.

BUCCI, Maria Paula Dallari. O conceito de política pública em Direito. São Paulo: Saraiva, 2006.

BUCCI, Maria Paula Dallari. Notas para uma metodologia jurídica de análise de políticas públicas. In Políticas públicas: possibilidades e limites, org. Cristiana Fortini, Júlio César dos Santos Esteves e Maria Teresa Fonseca Dias. Belo Horizonte: Fórum, 2008.

CAGGiAnO, Monica Herman Salem. Direito Parlamentar e Direito Eleitoral. São Paulo: Manole, 2004.

DI PIETRO, Maria Sylvia Zanella. Participação popular na Administração Pública. Revista de Direito Administrativo. Rio de Janeiro. 191:26-39, jan./mar. 1993. 
DI PIETRO, Maria Sylvia Zanella. Parcerias na Administração Pública. São Paulo: Atlas, 2015 .

FERRAZ, Anna Cândida da Cunha. União, Estado e Município na Constituição Federal: competências e limites. Cadernos FUNDAP. São Paulo. Ano 8, nº 15, abr/1988, p.42-47.

FISHKIN, James S.; LUSKIN, Robert C. e JOWELL, Roger. Deliberative Polling and Public Consultation disponível em http://cdd.stanford.edu/2000/deliberative-polling-andpublic-consultation/ Acessado em 19 maio 2015.

FURLAN, José Luis e CORROCHATEGOI, Nora. El Municipio como instrumento de desarrollo regional y la participación. IN: ESTESO, Roberto e TOCINO, Sergio (comp.), Municipio y Región. Buenos Aires: IIPAS e Fundación Friedrich Ebert, 1989.

GOMEZ, Alejandro. Municipalismo y proyectos políticos del gobierno militar. In: MÁRQUEZ, Daniel Alberto e PICONE, Francisco Humberto (Coord.). Temas de Derecho Municipal. Buenos Aires: Pensamiento Jurídico Editora, 1991.

GORDILLO, Agustín. La administración local argentina. In: MÁRQUEZ, Daniel Alberto e PICONE, Francisco Humberto (Coord.). Temas de Derecho Municipal. Buenos Aires: Pensamiento Jurídico Editora, 1991.

KRAUSE, Elton. A Formação da Política Municipal e as condições de elegibilidade. São Paulo: Memória Jurídica, 2002.

MARQUES NETO, Floriano de Azevedo. Ensaio Sobre o Juízo de Constitucionalidade de Políticas Públicas. Revista de Informação Legislativa. Ano 35, $\mathrm{n}^{\circ} 138$, abril a junho de 1998.

MARQUES, Paulo Eduardo Moruzzi. "Participação e Pronaf: um estudo do poder, dos atores e dos conflitos em torno dos conselhos municipais.” In: MARQUES, Paulo E. Moruzzi; SCHNEIDER, Sérgio; e SILVA, Marcelo Kunrath (org.). Políticas públicas e participação social no Brasil. Porto Alegre: Ed. UFRGS, 2004.

MÁRQUEZ, Daniel Alberto e PICONE, Francisco Humberto (Coord.). Temas de Derecho Municipal. Buenos Aires: Pensamiento Jurídico Editora, 1991.

PETRUCCI, Jivago. Gestão Democrática da cidade: delineamento constitucional e legal. Jus Navegandi. Teresina, a.8, n. 276. Disponível em http://jus.com.br/947515-jivagopetrucci/publicacoes. Acessado em 15 maio 2015. 
PINTO, Celi Regina J. Teorias da Democracia: diferenças e identidades na contemporaneidade. Porto Alegre: EDIPUCRS, 2004.

SANI, Giacomo. Participação política. In: Dicionário de política. 12. ed. Brasília: Universidade de Brasília, 2004. v.2.

SANTOS JÚNIOR, Orlando Alves dos. Democracia e governo local: dilemas da reforma municipal no Brasil. Rio de Janeiro: Revan, 2001.

SCHWARTZ, Germano. Sociologia Sistêmico-Autopoiética das Constituições. Porto Alegre: Livraria do Advogado, 2015.

VIANA, Oliveira. O Idealismo na Constituição. Rio de Janeiro: Terra de Sol, 1927. 